\title{
The Economic Impact and Dynamical Fluctuations Caused by The Flat Grass Scale Population, Aclerda Takahashii Kuwana (Hemiptera, Coccomorpha: Aclerdidae) Infesting Sugarcane in Alexandria, Egypt
}

\author{
Soad I. Abdel-Razak \\ Agricultural Research Centre, Plant Protection Research Institute, Scale Insects and \\ Mealybugs Dept., Alexandria, Egypt. E-mail: soadramadan@hotmail.com \\ current: University of Hafr Albatin, Faculty of Sciences, Biology Dept., Saudi Arabia
}

\begin{abstract}
The flat grass scale, Aclerda takahashii Kuwana, (Hemiptera, Coccomorpha: Aclerdidae) since its record for the first time in 1990 infesting sugarcane in Alexandria, Egypt, very little is known or published about the economic impact caused by this species, its seasonal fluctuation and assessed damage in sugarcane crop. Thus, the adopted study is focused in the palatability and impact caused by this pest as well as its annual dynamical fluctuation. Data obtained revealed that the estimated fluctuating densities of $A$. takahashii individuals on the stem of sugarcane plant, throughout both the following growing seasons of 2014-2015 and 2015-2016 proved two overlapping peaks for each. The obtained results also clarified that Aclerda takahashii mainly prefer the internodes of lower and medium parts of the sugarcane stem, compared with its upper part. Regarding the impact of Aclerda takahashii on the TSS\% (Brix), the obtained results showed that $A$. takahashii infestation reduce the Brix mean value (TSS\%) according to its incidence level which could be of economic concern.
\end{abstract}

Key words: Flat grass scale, Aclerda takahashii Kuwana, sugarcane.Egypt.

\section{INTRODUCTION}

In Egypt, sugarcane, Saccharum officinarum L considers the main source of sugar; sole source of molasses and a raw material for plywood and paper pulp industries. In Egypt, sugar cane production increased from 6.87 million tons in 1969 to 15.2 million tons in 2018. There is also a constant increase in the quantities of consumed sugar that turned Egypt from an exporter country at the beginning of the seventies to an importer country with about 2.6 million tons (Hassan, and Nasr, 2008).

Sugarcane plant is a long duration crop of $10-12$ months, therefore is liable to be attacked by a wide species of insect pests. It is infested by about more than 200 insects which cause heavy losses to the quality as well as the quantity of the crop (Kumar, et al., 2019).

Unfortunately, sugarcane usually infests with many species belonging to Super family: Coccoidea; heavy infestations by this group pest could reduce cane weight, juice brix, sucrose content and purity of the juice in addition to the reduced of cane yield and sugar recovery (Goel et al., 1983).

Aclerda takahashii Kuwana (Hemiptera: Coccoidea: Aclerdidae) is recorded for the first time in Egypt by (Karam, 1990) in Alexandria infesting sugarcane crop.

Unfortunately, very little is known or published about the economic impact caused by this species as well as, its seasonal fluctuation and detected damage in sugarcane crops elsewhere in sugarcane growing regions, even though it occurs in India, Egypt and China, and numerous islands in the Indian and Pacific oceons (Stocks, 2016). 
Flat grass scale, Aclerda takahashii Kuwana are not common in the United States and are likely to be confused with other scale or mealybug species, (Hodges and Hodges 2004; Hodges et al. 2008).

Of the aclerdid species for which information is available, many are reported to develop near or below ground level, but in the examined population of $A$. takahashii in USA, all stages were on the internodes of above-ground stem hidden beneath the leaf petiole (sheath). When the sheath was peeled back, crawlers to late adult females were seen commingled, often in abundance (Stocks, 2016).

The present paper through tights on the palatability; impact and Dynamical fluctuations of the Flat grass scale, Aclerda takahashii Kuwana (Hemiptera, occomorpha) infesting sugarcane in Alexandria, Egypt, which consider the first work focused on the economic impact caused by this pest in Egypt.

\section{MATERIAL AND METHODS}

\section{Dynamical fluctuations and infestation level of Atakahashii infesting sugarcane in Alexandria, Egypt.}

In order to investigate the dynamical fluctuations and infestation level of $A$. takahashii on sugarcane crop, Saccharum officinarum, an experiment was carried out in Sugarcane plantation at the Agricultural Research Station, Sabahia, Alexandria, Egypt on the selected sugarcane local varity- G396-75 along two years started from February, 2014 until January, 2016. A total of 10 sugarcane samples were examined monthly. Samples were chosen randomly having similar size, shape and height. The cuttings samples were transferred directly to the laboratory in order to count and classify the existing individuals of all inspected stages of $A$. takahashii as well as the Parasitized ones if. The infestation rate was calculated as percentage of samples actually taken in which the species was found. The rate of increase in population densities was calculated by dividing the mean number found in a sample data by that one found in the preceding data, (Bodenheimer, 1951)

Analysis of variance for comparing the mean of each monthly count was adopted by (Snedecor, 1970).

Palatability and impact of $A$. takahashii infesting sugarcane in Alexandria, Egypt.

In order to investigate the palatability and impact of $A$. takahashii (Hemiptera, Coccomorpha) on the infested sugarcane plants, Saccharum officinarum. A total of 10 sugarcane samples of the variety G396-75 were examined monthly from April until September, 2014 as well as the control. Samples were chosen randomly having similar size, shape and height. Each of sampled sugarcane replicates was measured and divided into three equals parts: the upper, the middle and the lower one. The cuttings of samples were transferred directly to the laboratory in order to count and classify the existing individuals of all stages of $A$. takahashii in each of the three cutting parts of each sample to determine the preference and palatability of the insect to infest each of the three parts of the sugarcane stem as well as measuring directly the total soluble solid, Brix percent (TSS\%) at $20^{\circ} \mathrm{C}$ in the laboratory in the three parts of every 10 samples of plants as well as the control using the Refractometer (0-32 ${ }^{\circ}$ Brix) (Ranganna, 1977) to measure the impact of infestation by the pest on the total 
soluble solid (Sucrose) in sugarcane Juice. Analysis of variance for comparing the mean of each monthly count was adopted by (Snedecor, 1970).

\section{RESULTS AND DISCUSSIONS \\ Infestation rate, and dynamical population density of $A$. takahashii Kuwana on sugarcane plant in Alexandria.}

Field observation was started in early February, 2014 up to January, 2016 to estimate the infestation rate (\%) of $A$. takahashii on sugarcane in Alexandria. Data presented in Table (1) clearly show the calculated monthly variations in infestation rate (\%). In the following growing season of (2014-2015), the infestation rate was comprised $100 \%$ during the investigation months except in December it amounted to $90 \%$.

The obtained data also showed that in the second growing season of 20152016) the same trend of infestation incidence was occurred; somewhat decreased till (90\%); (80\%) and (90\%) in November; December and January, respectively.

In general, the infestation rate of $A$. takahashii was very high during both of the investigation years of study, which mean that during most months of the year all inspected replicates of sampled months were infested with the pest, except in December, 2014 \&2015, it was decreased up to $90 \% \& 80 \%$ respectively; in November, 2015 it represented 90\% while in January, 2016 it reached 90\%.

The estimated dynamical changes in the population density of $A$. takahashii on sugarcane during both the successive growing seasons of 2014-2016 are also given in Table (1) and illustrated in Figure (1).

In the growing season 2014-2015; the calculated mean of counted individuals per plant In February 2014, In February 2014, comprised 33.9 \pm 12.5 pronounced increased in the second month reached $144 \pm 11.9$, then showed a pronounced decrease up to $13.3 \pm 12.8$ in April, 2014. Thereafter, the mean counted insects/plant increased again in May, 2014 to reach 21.9 \pm 14.4 ; followed slightly increased in June, July and August reached 27.7 \pm 11.6 ; $81.9 \pm 11.3$ and $109.6 \pm 14.8$ respectively; then decreased gradually during September, October, November and December 2014 up to January, 2015 represented $47.8 \pm 7.2,41.3 \pm 8.2,36.8 \pm 5.6,18.4 \pm 3.8$ and $10.3 \pm 2.1$ respectively. In the second growing season of 2015-2016 a merely similar trend of fluctuating calculations was also detected. The mean counted insects per plant was obviously higher during February, 2015, resembled 63 \pm 11 ; continued its increase up to $91.8 \pm 6.7$ in March; then gradually began to decrease again from $80 \pm 9.6$ in April 2015 and reached the minimum in May, 63.3 \pm 6.2 . Thereafter, that estimated mean increased again during August 108.2 \pm 8.9 ; then followed a gradual decrease in September $42.5 \pm 4.8$ and reached the minimal value of $32 \pm 4.8$ in October, November and December 2015 and January, $201632 \pm 4.8$, $32.7 \pm 2.9,17.1 \pm 1.3$ and $11 \pm 1.3$ respectively.

Herein, from these above mentioned results it could be shown that the estimated densities of fluctuating population of $A$. takahashii on the stem of sugarcane plant, throughout both the following growing seasons of 2014-2015 and 2015-2016 proved two overlapping peaks for each. From Fig. (1), the 1st 
occurred peak in the growing season of 2014-2015 was observed in March, 2014 comprised $144 \pm 11.9$ individuals; the second, from June until August 2014; reached the maximum of $108.2 \pm 8.9$ in August.

The 1st occurred peak in the growing season of 2015-2016 was observed in March, 2015 comprised 91.8 \pm 6 .7individuals; the second, from June until August 2015; reached the maximum of $108.2 \pm 8.9$ in August.

The quotient of increase (calculated by dividing the detected population density of any month by that of the preceding one, indicated that the exactly periods of occurring annual increase of the insect were March, July and November in the first growing season, their values were 4.2, 2.9, and 0.9. in the second growing season of 2015/2016 were April, July and November their values were 1.6, 1.3 and 1 respectively. It is worth to mention here that during the period of experiment no parasitized individuals or noticed parasitoid associating with this pest.

\section{Palatability and impact of $A$. takahashii to infest sugarcane stem parts in Alexandria, Egypt.}

the obtained results elucidated in figs 2 show that, $A$. takahashii during all the experimental period prefer the lower and medium parts of the infested sugarcane stem it reached its maximum in the lower and medium part of sugarcane stem in August with total count value of $51.6 \pm 16.3$ and $52.1 \pm 16.4$ respectively, versus a value of $3.2 \pm 1$ total count in the upper part of sugarcane stem. The data illustrated in Fig. 2 agree with that obtained by (Stocks, 2016) who mentioned that the insect stages were reported to develop near or below ground level, but in the examined population of $A$. takahashii in USA, all stages were inspected on the above-ground stem hidden beneath the leaf petiole (sheath) and when the sheath was peeled back, crawlers to late adult females were seen commingled, often in abundance.

Results presented in Figs.3; 4 and 5 show the effect of $A$. takahashii infestation level in the three different part of sugarcane stem on the TSS\% of the extracted cane Juice.

In the lower part of the sugarcane stem (Fig.3) the Brix was reduced to $19.9 \pm 6.3$ when the infestation was in its highest value, 51.6 \pm 16.3 in August. While it reached $24 \pm 6.4$ when the population of the insect was in its lower level 13.3 \pm 4.2 in April.

The same trend was noticed in the median part of sugarcane stem (Fig.4), the Brix was reduced to $19.8 \pm 6.2$ when the infestation was in its highest level, $52.1 \pm 16.4$ in August. compared with the Brix value of non-infested plant $26 \pm 5.4$.

The Brix in the upper part of sugarcane stem was $24 \pm 6.2$ in April with a total population of the pest $3.5 \pm 1.1$, while in the control it was $26.2 \pm 5.2$.

While the Brix was in its low level in August, $18.5 \pm 5.8$ with a total population of the pest $3.2 \pm 1$ and the control was $26 \pm 5.4$.

From the above cited results $\mathrm{t}$ could be revealed that infestation by $A$. takahashii population can reduce the mean value of Brix (TSS\%) according to the infestation level which can be of economic concern.

The data obtained agree with (Mohamed et al., 2009) who studied the effect of detected infestation level of Saccharicoccus Sacchari and its impact on TSS\% of sugarcane juice. They showed the effect of infestation on the estimated 
percentages of brix which was reduced by 4.95 and $13.47 \%$ due to the low and sever infestation, respectively.

\section{ACKNOWLEDGEMENTS}

Appreciation is extended to Dr. Ahmed Barakat, Field Crop Pests Department, Agricultural Research Centre, Plant Protection Research Institute, Alexandria, Egypt. for his support during the Experiment period.

Table (1). monthly variations in infestation rate (\%), total count per plant and quotient of increase of Aclerda takahashii infesting sugarcane at Alexandria (February, 2014 - January, 2016).

\begin{tabular}{lcccccc}
\hline \multirow{2}{*}{$\begin{array}{l}\text { Date of } \\
\text { inspection }\end{array}$} & \multicolumn{2}{c}{ Infestation rate (\%) } & \multicolumn{2}{c}{ Total count / plant } & \multicolumn{2}{c}{$\begin{array}{c}\text { Quotient of increase } \\
\text { (Q.I) }\end{array}$} \\
\cline { 2 - 7 } & $\mathbf{2 0 1 4}$ & $\mathbf{2 0 1 5}$ & $\mathbf{2 0 1 4}$ & $\mathbf{2 0 1 5}$ & $\mathbf{2 0 1 4}$ & $\mathbf{2 0 1 5}$ \\
\hline February & $\mathbf{2 0 1 5}$ & $\mathbf{2 0 1 6}$ & $\mathbf{2 0 1 5}$ & $\mathbf{2 0 1 6}$ & $\mathbf{2 0 1 5}$ & $\mathbf{2 0 1 6}$ \\
March & 100 & 100 & $33.9 \pm 12.5$ & $63 \pm 11.3$ & - & - \\
April & 100 & 100 & $144 \pm 11.9$ & $91.8 \pm 6.7$ & 4.2 & 0.6 \\
May & 100 & 100 & $21.9 \pm 14.4$ & $63.3 \pm 6.2$ & 1.6 & 0.8 \\
June & 100 & 100 & $27.7 \pm 11.6$ & $74 \pm 8.5$ & 1.3 & 1.2 \\
July & 100 & 100 & $81.9 \pm 11.3$ & $99.6 \pm 7.1$ & 2.9 & 1.3 \\
August & 100 & 100 & $109.6 \pm 14.8$ & $108.2 \pm 8.9$ & 1.3 & 1.1 \\
September & 100 & 100 & $47.8 \pm 7.2$ & $42.5 \pm 4.8$ & 0.4 & 0.4 \\
October & 100 & 100 & $41.3 \pm 8.2$ & $32 \pm 4.8$ & 0.9 & 0.8 \\
November & 100 & 90 & $36.8 \pm 5.6$ & $32.7 \pm 2.9$ & 0.9 & 1 \\
December & 90 & 80 & $18.4 \pm 3.8$ & $17.1 \pm 1.3$ & 0.5 & 0.5 \\
January & 100 & 90 & $10.3 \pm 2.1$ & $11 \pm 1.3$ & 0.6 & 0.6 \\
\hline
\end{tabular}




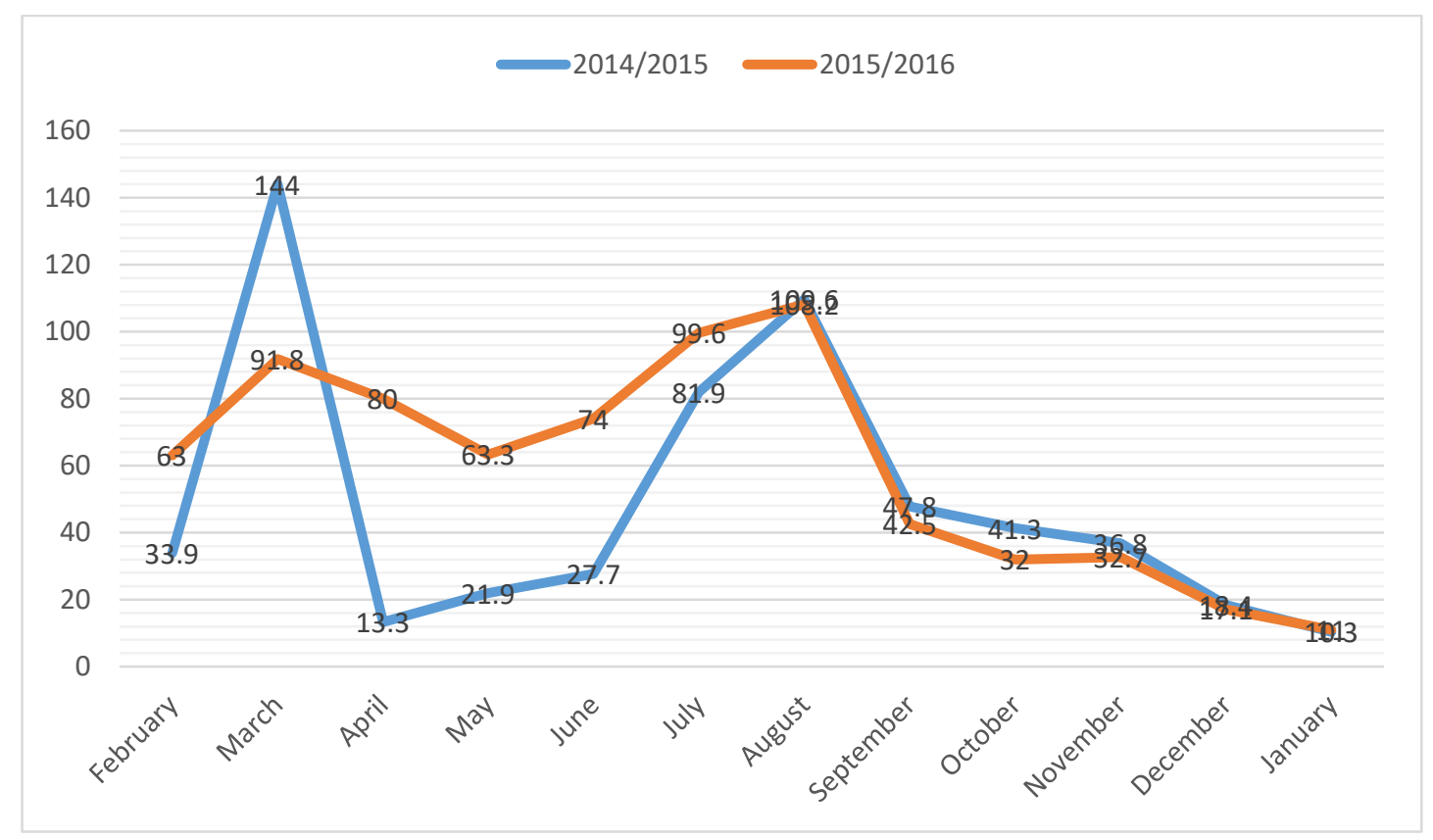

Fig.(1). Monthly variations in total count per plant of Aclerda takahashii infesting sugarcane at Alexandria (February, 2014 January, 2016).

Fig. 2: Palatability of $A$. takahashii to infest sugarcane stem parts

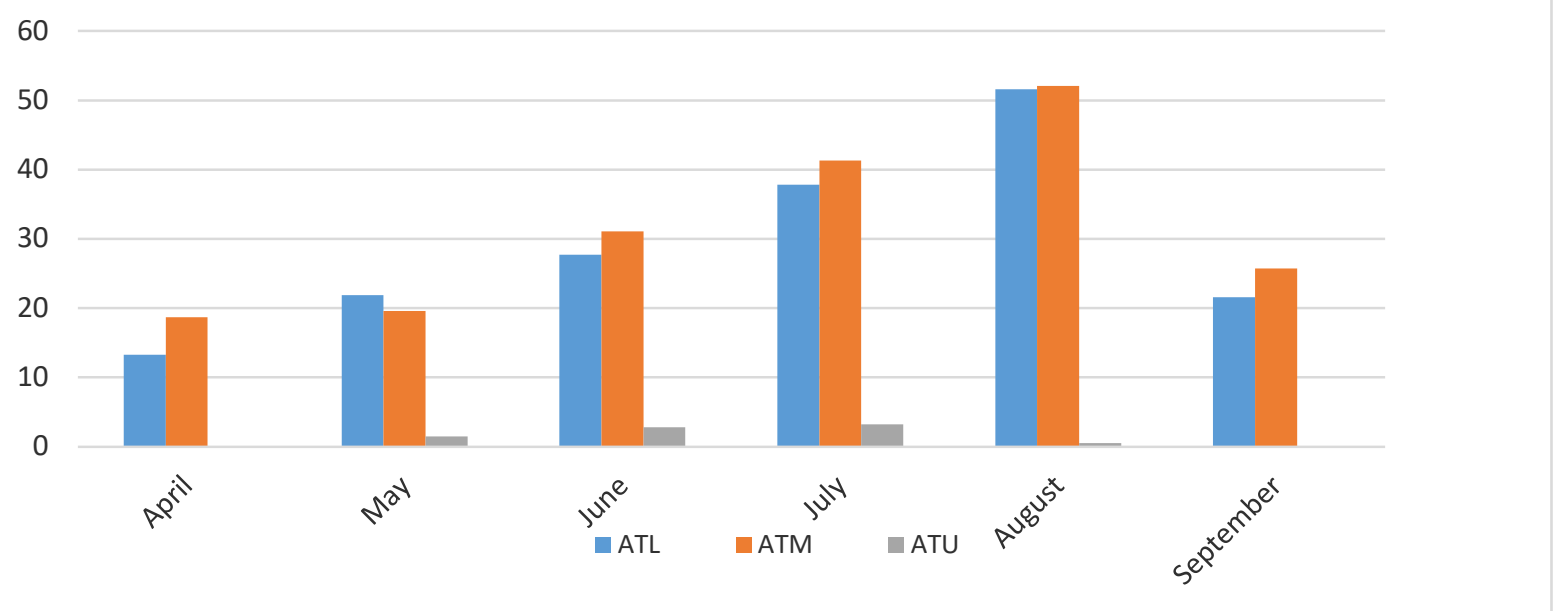

Fig. (2). Monthly variations in total count of Aclerda takahashii infestation on the lower (ATL); Middle (ATM) and Upper (ATU) of sugarcane stem part (February, 2014 - January, 2016). 
Fig.3: Monthly variations of $\boldsymbol{A}$. takahashii population in lower stem part and its relation with TSS\%

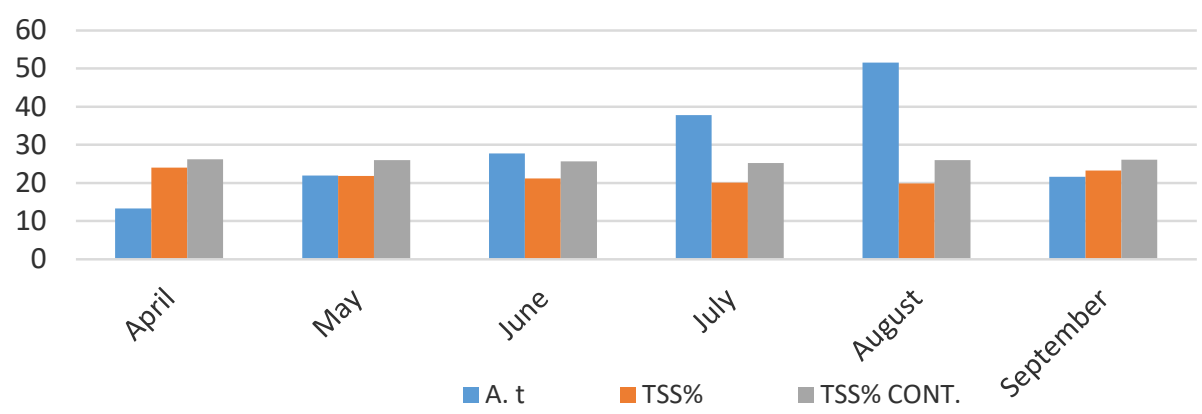

Fig.4: Monthly variations of $\boldsymbol{A}$. takahashii population in middle stem part and its relation with TSS\%

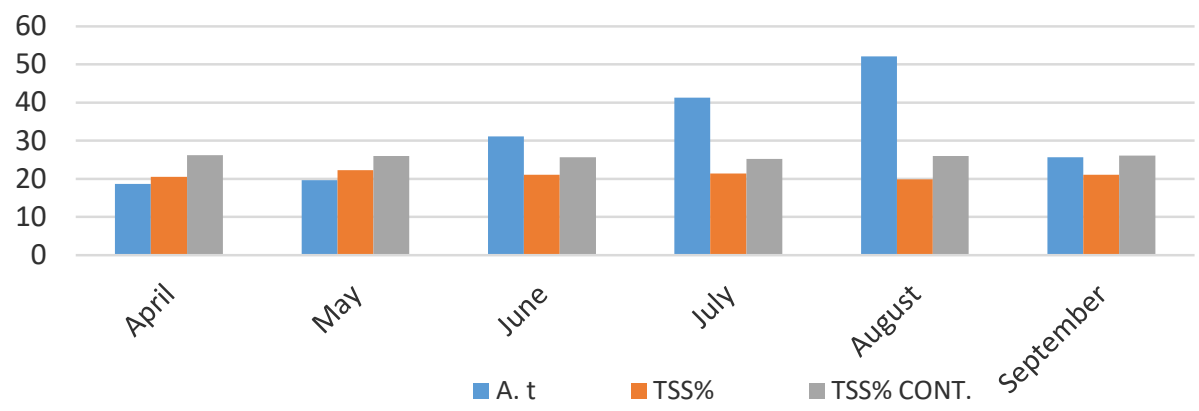

Fig.5: Monthly variations of $\boldsymbol{A}$. takahashii infestation in upper stem part and its relation with TSS\%

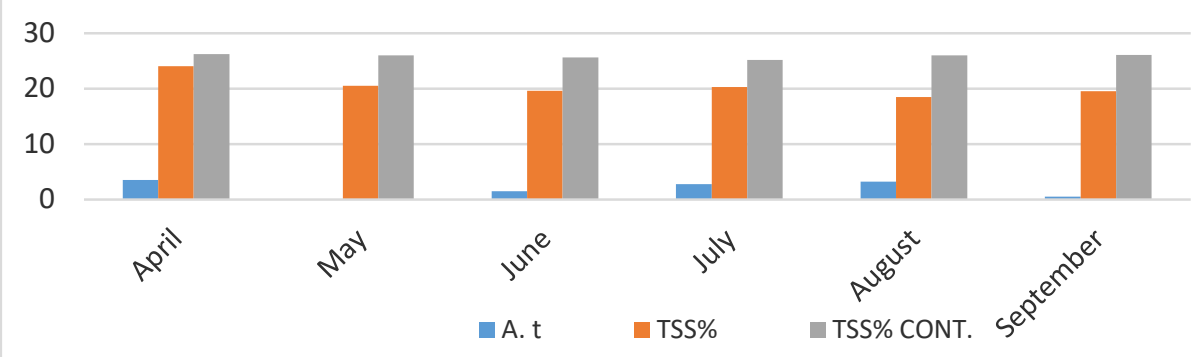

Figs. (3; 4 and 5). Monthly variations in total count of Aclerda takahashii infestation on the lower; Middle and upper part of sugarcane stem and its impact on TSS\% (February, 2014 - January, 2016). 


\section{REFERENCES}

Kumar, Anil; Pal, Suprakash and Chand, Hari. (2019) Insect Pests of Sugarcane and Their Management: An Overview. January 2019/n book: Advances in Agricultural Entomology (Volume-3) Publisher: AkiNik Publications, New Delhi, India (Editor: Ghoneim, K.)

Stocks, Ian. (2016) Pest Alert: The flat grass scale, Aclerda takahashii Kuwana (Hemiptera: Aclerdidae), a new pest of sugarcane in Florida. FDACS-P-01817 Pest Alert created October 2016. Florida Department of Agriculture and Consumer Services Division of Plant Industry.

file:///C:/Users/Dell/Downloads/2016_Aclerdatakahashii_PA\%20(2). pdf

Mohamed, Gamal El-Dein, H.; Ibrahim Sanaa, A. M. and Moharum, Fatma, A.(2009). Effect of Saccharicoccus sacchari (Cockerell) infestation levels on sugarcane physical and chemical properties. Egypt. Acad. J. biolog. Sci., 2 (2): 119-123.

Hassan, Soltan Foly and Nasr, Mahmoud Imam. (2008). Sugar industry in Egypt. Sugar Tech (2008) 10(3): 204-209.

Hodges, A., G. Hodges, L. Buss, and L. Osborne. (2008). Mealybugs and mealybug look-alikes of the southeastern United States. North Central IPM Center. Available at: https://firstdetector.org/static/pdf/mealybugs. pdf.

Hodges, G.S. and A. Hodges. (2004). New invasive species of mealybugs, Palmicultor lumpurensis and Chaetococcus bambusae (Hemiptera: Coccoidea: Pseudococcidae), on bamboo in Florida. Florida Entomologist 87(3): 396-397.

Karam, Hedaya H. (1990). Aclerda takahashii Kuwana (Homoptera: Coccoidea - Aclerdidae) a Scale Insect Recorded for the First Time in Egypt. Alex. J. Agric. Res. 35 (2): 127-134.

Goel, S.C., and Raghunath, T.A.V.S. and Goel. S.C (1983) Losses due to scale insect in sugarcane variety CO- A 7602. (In) Insect Ecology and Resource Management. Goel, S.C. (Ed) (Pb) Santan Dharm College, Muzaffarnagar, India: 142-146.

Ranganna, S. (1977). Manual of analysis of fruit and vegetable productsMcGraw-Hill, New Delhi: Tata.

Snedecor, G. M. (1970). Statistical methods applied to experiments in Agriculture and biology. lowa state press, USA: $534 \mathrm{pp}$.

Bodenheimer, F. S. (1951). Citrus entomology in the Middle east. (Text Book). 


\section{الملخص العربي}

\section{Aclerda takahashii الأثر الأقتصادى والتغيرات الايناميكية لحشرة}

\section{التي تصيب قصب السكر (Hemiptera: Coccomorpha: Aclerdidae)}

\section{الإسكندرية ، مصر . الإن. \\ سعاد ابراهيم عبد الرزلق}

مركز البحوث الزراعية ، معهد بحوث وقاية النبات ، قسم الحشرات والبق الدقيقي ، الإسكندرية ، مصر. جامعة حفر الباطن ، كلية العلوم ، قسم الأحياء ، المملكة العربية السعودية soadramadan@hotmail.com

حشرة Aclerda takahashii منذ تسجيلها لأول مرة في مصر في عام 1990 على محصول قصب السكر في الإسكندية لم يُعرف أو يُنشر سوى القليل جدًا عن التأثثر الاقتصادي الذي تسببه على محصول قصب السكر وكذلك التغيرات الموسمية لعشائرها. ولذلك ركزت هذه الدراسة على التفضيل والتأثير الذي تسببه هذه الآفة وكذلك عدد أجيالها وعشائرها. أظهرت النتائج التي نم الحصول عليها أن تعداد الأفة على ساق نبات قصب السكر ، خلال موسمي الزراعة التاليين 2014-2015 و 2015-2016 أثبت وجود جيلين ممتدين لهذة الحشره . وأوضحت النتائج كذلك ان الحشرة خلال كل فتزة التجربة تفضل الجزء السفلي والوسطي من ساق نبات قصب السكر مقارنة بالجزء العلوي. أما فيما يتعلق بتأثثر الأفة على TSS\% (نسبة المواد الصلبة الذائبة الكلية) أظهرت النتائج المتحصل عليها أن تعداد الحشرة قد قلل من نسبة المواد الصلبة الذائبة الكلية والذي يعتبر مصدر قلق اقتصادي. 